\title{
IDENTITY AND BIAS IN PHILOSOPHY: WHAT PHILOSOPHERS CAN LEARN FROM STEM SUBJECTS Yasemin J. Erden
}

This article centres on two distinct but intersecting questions: (1) does it matter if we cannot definitively answer the question 'what is philosophy?' and (2) do philosophers exhibit bias? The article will answer 'yes' to both questions for the following reasons. First because the uncertainty has allowed some answers to dominate. Second, because the answers necessarily demonstrate biases, and these have led to a lack of diversity in the discipline. Following this, the article will consider why philosophers have been slow or reluctant to accept that bias plays a role in what we do. This lack of recognition has, I suggest, limited opportunity for diverse approaches, methods, and standpoints to flourish. The discipline has suffered as a result, and so too have diverse philosophers. Many fields in science, technology, engineering and mathematics (STEM) meanwhile have sought to tackle the lack of diversity head on, and philosophers would do well to heed their examples.

\section{Introduction}

How would you know if you were biased? And if you knew that you were, and considered that you ought not to be, how could you change? These questions may not be the terms of the Creative Commons Attribution licence (http://creativecommons. org/licenses/by/4.0/), which permits unrestricted re-use, distribution, and reproduction in any medium, provided the original work is properly cited.

Think 59, Vol. 20 (Autumn 2021) 
easy to answer, so to examine what's at stake, let's consider some simpler questions first.

The first is one that my former colleague Dr Hannah Marije Altorf used to ask our students (and which forms the title of her article in this collection), namely: what does a philosopher look like? Consider the question for a moment. What do we look like? There is no point denying that you $\infty$ have expectations, and that those expectations will have arisen from a combination of what you have seen, understood, experienced, and what you believe. I find that the best students (indeed also philosophers) tend to be those who are most honest, and those honest and good students with whom we talked admitted that they expected philosophers to be white and male. Since we were women (and I am multicultural) we did not meet those expectations. Thus, the expectation and thereby the bias was challenged, even if it might not have been fully overcome. Indeed, those honest students are not alone, and the ubiquity of this bias is demonstrated in conferences and talks where people rarely hide their surprise at my profession. And when they try, they often do so badly. Many women and diverse philosophers, whether in terms of approach, method, standpoint, or identity, report having experienced the same.

The second simple question comes from George Yancy's 'Dear White America', published in 2015. In that article he asked, 'What if I told you that I'm sexist?' His blunt answer was, 'Well, I am'. He suggests this prejudice is particularly problematic because he is an academic philosopher, and thereby expected to be enlightened. Yet, he notes, there were times when he failed to speak out against sexism, and to live by the values against which enlightenment is measured. He asks the reader to consider their own biases in return, and specifically their racism.

From the above discussion, three points should now be clear. First that bias is to some extent unavoidable, second that philosophers are far from immune to bias, and finally that a failure to recognize one's own fallibility in these 
respects both demonstrates and perpetuates such bias. To sincerely answer each of the above questions requires selfreflection, honesty, vulnerability, and openness: to acknowledge that one is biased. These are qualities that are valued in philosophy, but the practice of such virtues is not always valued or rewarded. The programme where my colleague and I engaged students in these methods was closed, and Yancy's article received backlash, including from philosophers. I suggest that the lack of will to acknowledge and confront one's own bias is itself a demonstration of said bias. To defend this claim I should say more about what I mean by 'bias'.

Bias as a term captures all the preferences and tendencies, from the banal to the harmful, that necessarily arise from a life that is lived. This includes all kinds of expectations, beliefs, judgements, and actions. Though the term is often used to express negative connotations, such as selfish or prejudicial preferences, it is also associated with ordinary, everyday decision-making, like a preference for this type of coffee over another. When people express their intention to be neutral or objective, they seek to override such bias, and maybe with some success. At other times biases are simply denied or masked, though the consequences of a bias cannot be as easily hidden. Historically philosophers have rather failed to address this.

Highly valued methods in what is now described as Analytical (or Anglo-American) Philosophy typically encourage the philosopher to shed their subjective position and to prioritize the rational over the personal. Thought experiments encourage those same philosophers to speculate about what the subjective might be in highly theoretical contexts, and to believe that such positions are indeed within one's intellectual grasp. It is in this context that the philosopher who reflects on the identity of their discipline, for instance by answering the question what is philosophy?, does so with the belief that their answer will be rational, and not particularly biased.

But is it really the case that the subjective can be shed in this way, and does imagination offer a way to truly 
understand what has not been experienced? In line with many feminist philosophers, I suggest that such methods are in fact insufficient for such strong conclusions. Instead, the subjective, embedded, and embodied experience that each person has by necessity plays a not insubstantial role in both a person's thinking and their being. A failure to acknowledge this, coupled with the openness of philosophy's identity, has left the discipline subject to the biases of those with the power and voice to answer the question where it counts most. This has had the outcome that diverse members of our discipline have simply been excluded. Further examination of this point will therefore be the starting point of this article.

Those who deny their vulnerability to bias, and who make a virtue of their honing and valuing of rationality, or their capacity for imaginative engagement of the position of the 'other', have, I suggest, been falsely led to believe that they can doubt and question everything, including their own presuppositions. On this account, the philosopher who fails to fully acknowledge and address their biases runs the risk of perpetuating them. Such circumstances are exacerbated by the kind of overconfidence that begets limited humility, and which goes hand in hand with the failure to recognize one's own limitations or the parameters that define the capacity for reason. Discussion of this point, alongside how this has perpetuated the status quo, will form the second section of this article.

In the final section, we'll consider how those in science, technology, engineering, and mathematics (STEM) have sought to tackle the lack of diversity head on, and what philosophers can take from those examples.

\section{The Perpetual Identity Crisis: From What Philosophy Is to Who Decides}

Philosophers and non-philosophers alike regularly ask what is philosophy? It is an important question, and yet not 
an easy one. More than this, the tendency of philosophers to be dissatisfied with simple answers, even when those same answers might appear uncontroversial to non-philosophers, has meant that theoretical resolutions of the question are not expected to satisfy all philosophers. Indeed, the question is never considered to be closed, at least in theory. In practice, however, the question must be answered, and such answers are often resolute. Textbooks, thinkers, subjects, courses, departments, and academics are grouped within definitions of philosophy that are accepted more or less grudgingly. In the giving of these answers, divisions are created and boundaries enforced, with philosophers positioned either in or outside the scope of the subject. Philosophers succeed or fail according to the metrics against which they are measured, including in the UK within the Research Exercise Framework (REF), which is a method by which the quality of research and researchers (in this case philosophers) is evaluated. Such metrics necessarily give preference to some definitions, styles, and approaches over others, and it seems uncontroversial to acknowledge that these tend to reflect those traditional and dominant approaches.

Interdisciplinary fields of philosophy, such as those that engage with science and technology, have not always been accepted as philosophy in such exercises, and terms like pure are sometimes offered in the analysis. Thus, the question of what is philosophy has a practical outcome, and methods for assessment include not only consideration of the work, such as methodology and approach, but also the researcher, including their training. Yet not all philosophical training or methods are the same, and not all philosophers share sufficient similarities of value or approach such that we can sufficiently understand and engage with each other. So, the decision about where those boundaries are drawn necessarily engages the preferences and training of those who draw it.

This issue is not unique to philosophy, but it is also not common among all disciplines. In fact, few other 
professions and fields question their own identity as frequently or habitually as philosophers. What it is to be science or technology is found in the practice of those disciplines, and since those practices often contain quite specialized methods, tools and processes, the lines can be (more or less) easily drawn. There are of course grey areas, but on an average day, in an average lab, the average scientist or engineer can go about their teaching and research without having to begin with the question of identity. The same is largely true for many subjects in the social sciences and in the humanities. This is not to say that questions of disciplinary identity do not arise, and there are certainly many who challenge the status quo, especially where distinctions and definitions are unfair or otherwise problematic. But they are not required to do so, and the question does not by necessity arise.

One discipline where the question of identity is raised with similar frequency is art. The question 'what counts as art?' is ubiquitous not only in the field, in aesthetics, in philosophy of art, but also for artists and those who engage with art as consumers, enthusiasts, buyers, and traders. The success, career, wealth, and even life and death of an artist can be profoundly affected by the answer given to the question. Part of the difficulty is that in principle anything could be considered art, but in reality not everything will be accepted as art. Whether a piece of work makes the grade will depend on many features: tradition, economy, power, preference, and ultimately judgement - of the many or more commonly, of the few. This process of reason, judgement and acceptance illustrates the structure and rationality of human decision-making, but it also throws into sharp relief the biases, disparities, inconsistencies, and even arbitrariness that accompany such methods. Art is especially vulnerable because it is in the temperament of many artists and creative folk generally to challenge boundaries, question authority, and look to see things anew. And here is another key overlap with philosophy. Just as artists reframe the parameters of art, philosophers 
constantly examine our discipline. Though the structures and rules may not be the same, and the temperament of artists and philosophers may differ, the tendency to question even that foundation upon which your work and being relies seems to me essential in the arts and philosophy in a manner not required for other disciplines.

To ask what is philosophy therefore expresses more than just simple curiosity. Beyond a question about identity, it is also partly an expression of an identity. To ask the question is partly to do philosophy, and to understand this is to begin to understand that being part of the discipline involves the asking of questions, even those which seem simple or banal. Yet this tendency and the resulting scope for uncertainty have practical ramifications for both group identity and the experience of individual philosophers. In simple terms, the answer that is selected cannot rely on the same certainty of methods (tools, processes, outcomes) as per other disciplines. This, I suggest, makes philosophy susceptible to bias.

Feminist philosophers have for many years shown that philosophy tends towards a status quo that excludes the 'other', yet philosophers inside the academy remain confident in their judgement about what is good or compelling philosophy, and whose work satisfies those conditions. Decades of argument and evidence (including statistics and comparisons) to the contrary have done little to dent this confidence. The consequences have been substantial for those who have been excluded from the academy and for the corpus of work that is typically included in the canon. Meanwhile the work of those on the outside is routinely dismissed, ignored, or denigrated. ${ }^{1}$ Changes have been made, but slowly, and we need to reflect on why this has been the case. In simple terms, why has a discipline with examination and reflection at its heart, including about its own identity, been so slow to accept and address the failures that feminist philosophers have shown so robustly? 


\section{Over-Confident Reasoning and the Inevitability of Bias in Philosophy}

In fact, the question of bias in philosophy strikes at the very core of a discipline which, many champions believe, is necessarily critical and open to challenge and scrutiny. The belief that philosophers challenge what others merely accept is stated widely and proudly. Yet are such claims true?

In 2013, a researcher sought to compare the rate at which the works of male philosophers and female philosophers were cited. His study looked at the most-cited pieces from 1993 to mid-2013 in top philosophy journals. The idea of 'top' included ideas like well-known, high circulation, high impact, good reputation, and so on. These journals were Nous, Mind, Journal of Philosophy, and Philosophical Review. Of the 520 top cited items in these journals during a 20-year period, the researcher noted that only 19 were by women (15 distinct authors), which represented just 3.6 per cent of the total. Meanwhile, 6.3 per cent of the pieces were by David Lewis. ${ }^{2}$

In a similar vein, another study measured the number of publications by black philosophers in the US (described as 'US BIPs'), across 15 journals (including some of those publications noted above) between 2003 and 2012. The author found that publications by black authors were few. In fact,

there were 30 publications by US BIPs for all journals during this period. By contrast, there were 10659 publications overall during this period. This means that publications by US BIPs were $0.28 \%$ of the publications during this period. Of the 30 publications, 15 were research articles as opposed to book reviews. There were 7638 research articles overall in this period, meaning that research articles by US BIPs were $0.19 \%$ of the research articles published. ${ }^{3}$

If philosophers are neutral and objective, then what do these discrepancies indicate? Is this a result of intentional 
negative bias or prejudice, or habit and narrow scholarship? It is not evident that the work of women or minority philosophers has been overlooked intentionally, but it is also clear that such work has been, and in many cases still is, overlooked. Where other attributes are considered, such as inclusion of those with disabilities, the numbers dwindle further. In 2012/13 for instance, disabled people comprised only ' $4 \%$ of full-time faculty in philosophy departments in the US' and 'less than 1\% of full-time faculty in philosophy departments in Canada.' ${ }^{4}$ Even if the causes may be difficult to establish, the disparity is evident.

If the expectations are that a field like philosophy offers objective arguments, with results that are somehow neutral, logical, reasonable, then this can perpetuate the view that the problems exist elsewhere. In the case of publications, for instance, if the belief is that such processes are reasonable and fair, yet fewer minority groups are included, then this can perpetuate the myth that minorities are not philosophers. To believe that would be to exhibit the kind of bias that I describe in the introduction, yet to challenge it requires that we think more about how this situation has arisen.

Part of the issue is that it not easy to understand the position of the other, even if thought experiments would suggest otherwise. Similarly, it's not easy to imaginatively experience what the other perceives. The common postexperience exclamation of 'I didn't understand it until I experienced it' are familiar and should give the philosopher pause for thought. What would you do if... questions encourage the reader to consider what it is to be in the position of the other, but they can also lead them to falsely assume knowledge and understanding of the other, as well as to develop a false confidence in one's ability to sufficiently empathize or to know what each concrete position involves.

To recognize the concrete experience as a valuable contribution to being a philosopher requires that we see philosophical debate, research, and engagement as necessarily 
involving the exercise of our biases, preferences, prejudices, opinions, hopes, and wishes, as well as a good proportion of our ignorance, naivety, false expectations as well as beliefs regarding our own identities and abilities. In other words, our respective (in)capacities for objectivity. Wittgenstein saw this when he criticized academics who thought they could view things fully objectively, as if somehow from above or outside the world of experience. In a note written to Sraffa in 1935 he describes the thinking of 'Cambridge people':

Here are people who try to speak in a queer way 'impartially' about things, they pretend to be able to slip out of their own skins and they speak as though they could understand everybody's feelings, wishes, tendencies etc. ${ }^{5}$

It is partly out of these kinds of concerns that he develops the motif of the language-game, ${ }^{6}$ which evokes a sense in which understanding language requires involvement in that language. Just as we understand a game - how it is played and the rules - through playing/watching the game, we understand a language by using it. We can no more view our language from an objective perspective than we can slip out of our skin, and I would suggest that the same limitations apply to understanding our own biases on the one hand, and those of our discipline on the other. The failure to recognize this, and to recognize how this has fed into the status quo of philosophy, has brought us to the position where exclusion has been too often accepted, and the value of diversity largely ignored.

\section{What Philosophy Can Learn from STEM, and Why Philosophy is Closer to Art than Science}

It's no secret that STEM subjects have their own problems with bias. This includes the over-representation of young white male students in scientific experiments, the 
design of technologies for primarily male able-bodied people, the failure of image recognition software to recognize non-white faces and skin, and the tendency of a scientific output or a technology to display the same biases as their developers, to name but a few examples. Until recently those in STEM were likely to be male, and their research tended to replicate their own biases, preferences, experiences, and expectations. The issues noted above therefore stem partly from poor data, methodology, and design, as well as from a lack of representation and diversity among the researchers themselves.

Yet many STEM subjects have now advanced far beyond philosophy in terms of both their recognition of the problem and the proactive measures taken to tackle the issues. These began with the recognition and acceptance that STEM subjects are embedded in social and economic systems and that these structures play a role in the practices and outcomes of the work. Such conclusions led to the adoption of methods that seek to prevent negative outcomes and to engage a wider variety of people with a stake in the innovations or developments. The point is not that such methods are always successful, but rather that the adoption of those methods indicates an intention and a willingness to address the issues directly. These methods include those focused on responsible research and innovation, the use of social (and newly ethical) impact assessments, and the application of value-sensitive or ethical design to STEM research, development, and implementation. What is striking is that while philosophers have played a key role in the development of such methods, and indeed many hold leading roles championing approaches like ethical design, yet the discipline of philosophy has failed to engage similarly robust methods of oversight for its own practices.

It is clear and obvious that STEM research requires ethical oversight, and reasons for this can be easily found in some of the unpleasant histories of those subjects. The results of STEM research impact people directly, including 
researchers and participants of study, and with implications that ripple out beyond the laboratory into a world of various inhabitants, sentient and otherwise. Yet the contributions of philosophy are not similarly assessed. That philosophy's impact on the world may be less does not mean we can ignore the ethical implications of the work that we do and the decisions that we make, including for our own researchers. Philosophical research rarely requires ethical oversight in formal terms, but we do ourselves a disservice if we take for granted that we are good people who would not be unethical. Especially given that so doing means that we continue to participate in a system that has for so long accepted philosophical ignorance, prejudices, and harms as acceptable but irrelevant side effects of being human (Kant's and Aristotle's racism and sexism are just two familiar examples).

We rightly expect that those in STEM should pay attention to the impact of their work on their researchers and participants, and on society generally, and we ask them to consider the circumstances in which their work is conducted. Yet we do not expect that an individual person working in STEM can make such assessments alone. Ethical oversight therefore requires the consensus of a diverse cross-section of researchers and stakeholders. I suggest that philosophers might consider doing the same, and to begin by inviting diverse philosophers not only to join the established status quo of philosophy as they find it, but to invite them to evaluate it ethically and critically with a promise to change those structures and tendencies that are found to be wanting. Only by taking seriously their perspectives, and effecting change as a result, can we be confident that we've really done as much as we can to avoid the biases of those who already occupy the space where such decisions have historically been made.

In his description of technology, Winner implores us to acknowledge 'that the technological deck has been stacked long in advance to favour certain social interests, and that some people were bound to receive a better hand than 
others'. ${ }^{7}$ Only when those philosophers with most power are willing to do the same, and to question their confidence in their own objectivity, can we reach sufficient ethical oversight of our own discipline.

\section{Conclusion}

Just as with art, while in theory anything could be considered philosophy, in practice what is valued and prioritized has depended on whose answers are heard and accepted. Diverse perspectives help to show the biases in those answers, yet the implications of this have for too long been ignored. Individual philosophers are concretely situated, with associated preferences and biases, and experience cannot be supplanted by theory; a thought experiment will only take you so far. This discord between experience and theory, and associated ethical implications, is central to feminist accounts of epistemology, but has not yet gained sufficient traction as a powerful method by which to fully critique our discipline.

The standardly philosophical question about the identity of philosophy remains open in the theoretical, but closed in the practical, and this has had wide-reaching negative consequences. It remains the case that those who hold much of the power in the discipline of philosophy are also those who define its identity. Philosophers necessarily shape the discipline by their own lights. Those with large platforms, dominant voices, and who benefit from a surplus of assumed credibility have a greater opportunity to participate in that shaping. So, what is philosophy: who can say?

Yasemin J. Erden is Assistant Professor in Philosophy at the University of Twente, NL. She is the author of many papers on interdisciplinary topics, including artificial intelligence, psychiatry, and nanotechnology.y.j.erden@ utwente.nl 


\section{Notes}

${ }^{1}$ See for instance Alcoff (1996), Benhabib (1992), Haraway (1988), as well as the collection of essays in Hutchison and Jenkins (2013). Erden and Altorf (2020) explores the practical consequences in more detail.

${ }^{2}$ Healy (2013).

${ }^{3}$ Bright (2016). Cf. Evans and Yancy (2016), Morgan (2016), Weinberg (2014).

${ }^{4}$ Tremain (2014).

${ }^{5}$ McGuinness (2007: 235 n. 7).

${ }^{6}$ Wittgenstein (2001).

${ }^{7}$ Winner (1980: 125-6).

\section{References}

Alcoff, L. M. (1996) 'Is the Feminist Critique of Reason Rational', Philosophic Exchange 26.1: 59-79.

Benhabib, S. (1992) 'The Generalised and the Concrete Other', in Situating the Self: Gender, Community and Postmodernism in Contemporary Ethics (Cambridge: Polity Press), 148-77.

Bright, L. K. (2016) 'Publications by Black Authors in Leiter Top 15 Journals 2003-2012', The Splintered Mind, <http:// schwitzsplinters.blogspot.co.uk/2016/01/publications-by-blackauthors-in-leiter.html> [accessed 28 June 2021].

Erden, Y. J. and Altorf, H. M. (2020) Difficult Women in Philosophy: Reflections from the Margin', Symposion 7.2: 239259.

Evans, B. and Yancy, G. (2016) 'The Perils of Being a Black Philosopher', The New York Times, 18 April.

Haraway, D. J. (1988) 'Situated knowledges: the science question in feminism and the privilege of partial perspective', Feminist Studies 14.3: 575-99.

Healy, K. (2013) 'Citation Networks in Philosophy', <https:// kieranhealy.org/blog/archives/2013/06/24/citation-networks-inphilosophy-some-followup/> [accessed 28 June 2021].

Hutchison, K. and Jenkins, F. (2013) Women in Philosophy: What Needs to Change? (Oxford: Oxford University Press).

McGuinness, B. (2007) 'What Wittgenstein Owed to Sraffa', in Chiodi, G. and Ditta, L. (eds.) Sraffa or an Alternative Economics (Basingstoke: Palgrave Macmillan), 227-35.

Morgan, W. (2016) 'Why Is My Professor Still Not Black?', Times Higher Education, 14 March. 
Tremain, S. (2014) 'Disabling Philosophy', The Philosopher's Magazine 65.2: 15-17.

Weinberg, J. (2014) 'Blacks in Philosophy in the US', Daily Nous, <http://dailynous.com/2014/08/28/blacks-in-philosophyin-the-us/> [accessed 28 June 21].

Winner, L. (1980) 'Do Artifacts Have Politics?', Daedalus 109.1: 121-36.

Wittgenstein, L. (2001) Philosophical Investigations (Oxford: Blackwell).

Yancy, G. (2015) 'Dear White America', New York Times, 24 December. 